\title{
Expression of the NR3A Subunit of the NMDA Receptor in Human Fetal Brain
}

\author{
HELENA T. MUELLER AND JAMES H. MEADOR-WOODRUFF \\ Department of Psychiatry and Mental Health Research Institute, \\ University of Michigan Medical School, Ann Arbor, Michigan 48109-0720, USA
}

KEYWORDS: NMDA receptor; schizophrenia; NR3A subunit; human fetal brain

NMDA receptors (NMDARs), a specific class of glutamate receptors, play an important role in many normal and pathological processes in the brain. NMDARs are ligand gated ion channels comprised of heteromeric assemblies of subunits encoded by seven different genes (NR1, NR2A-2D, and NR3A-3B). Distinct pharmacological, physiological, and signal-transducing properties are associated with each subunit, indicating that fundamental properties of NMDARs are in part determined by subunit composition. ${ }^{1}$ Changes in subunit composition may in turn underlie pathophysiological alterations linked to NMDAR dysfunction.

There is growing evidence that glutamatergic dysfunction may be involved in the pathophysiology of schizophrenia; in particular, it has been hypothesized that the activity of the NMDAR is decreased in this illness. ${ }^{2}$ Several studies examining the expression of the NR1 and NR2 subunits in schizophrenia have found brain regionspecific changes in transcript levels for these subunits in schizophrenia. ${ }^{3}$ Expression of the NR3A subunit has not yet been investigated in schizophrenia.

Previous studies, however, do provide evidence that the NR3A subunit may act as a unique and important modulator of NMDAR activity and function. In rodents, incorporation of the NR3A subunit into NR1/NR2-containing receptors decreases NMDAR activity. ${ }^{4}$ NR3A can also indirectly modulate NMDAR activity by altering the phosphorylation state of the obligatory NR 1 subunit, ${ }^{5}$ and when coassembled with NR1, generates a functional excitatory glycine receptor. ${ }^{6}$

Anatomical data in rodents also indicate that the NR3A subunit is highly expressed in brain regions implicated in schizophrenia, including prefrontal cortex, thalamus, hippocampus, and amygdala. Many of the abnormalities observed in these regions in schizophrenia are thought to be associated with abnormal developmental processes occurring during the second trimester of pregnancy. ${ }^{7}$ Collectively, these data suggest that alterations in NR3A expression may also contribute to NMDAR dysfunction implicated in schizophrenia.

\footnotetext{
Address for correspondence: Helena T. Mueller, Mental Health Research Institute and Department of Psychiatry, University of Michigan, 205 Zina Pitcher Place, Ann Arbor, MI 48109-0720. Voice: 734-936-2061; fax: 734-647-4130.

hmueller@umich.edu
}

Ann. N.Y. Acad. Sci. 1003: 448-451 (2003). (c) 2003 New York Academy of Sciences. doi: 10.1196/annals.1300.049 


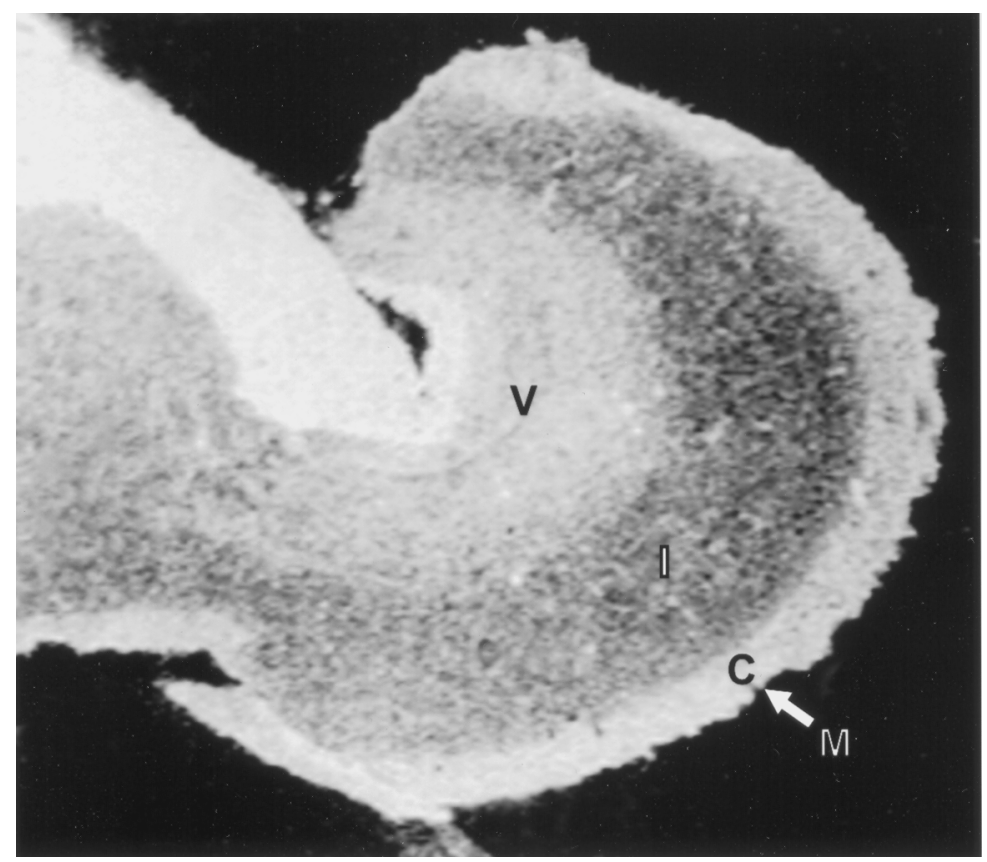

FIGURE 1. NR3A mRNA expression in the human fetal cortex. In situ hybridization was performed using a $\left[{ }^{35} \mathrm{~S}\right]$-labeled riboprobe containing a subclone for the rat NR3A subunit (NCBI GeneBank accession number AF073379, nucleotide coding region1139-1676). Transcript for the NR3A subunit of the NMDA receptor was detected in all four cortical layers in the developing human neocortex. Abbreviations: $\mathrm{M}=$ marginal zone, $\mathrm{C}=$ cortical plate, $\mathrm{I}=$ intermediate zone, $\mathrm{V}=$ ventricular zone.

To begin to characterize NR3A expression in human brain and determine if the NR3A subunit is expressed at an appropriate time in human brain development to play a role in the etiology of schizophrenia, we examined NR3A transcript levels by in situ hybridization in human fetal cortex. Human fetal tissue was obtained from Dr. Alan Unis, University of Washington, and has previously been described in an earlier report. ${ }^{8}$ The riboprobe used for this study was synthesized from a linearized plasmid containing an NR3A subclone (NCBI GeneBank accession number AF073379, nucleotide coding region1139-1676) and labeled with $\left[{ }^{35} \mathrm{~S}\right]$. NR3A mRNA was detected in all layers of the developing cortex (FIG. 1) at different gestational weeks within the second trimester (FIG. 2). NR3A mRNA was especially prominent in the marginal and ventricular zones during this time, which corresponds to a period of cortical migration in human cortical development, ${ }^{9}$ suggesting that NR3A may play a role in cortical migration. Interestingly, NMDARs are known to be involved in cortical migration ${ }^{10}$ and there is evidence of abnormal cortical neuronal migration in schizophrenia. ${ }^{11,12}$ Another developmental abnormality observed in schizophrenia is decreased dendritic spine density in the cortex and mice lacking NR3A show increased 
NR3A mRNA expression in human fetal cortex

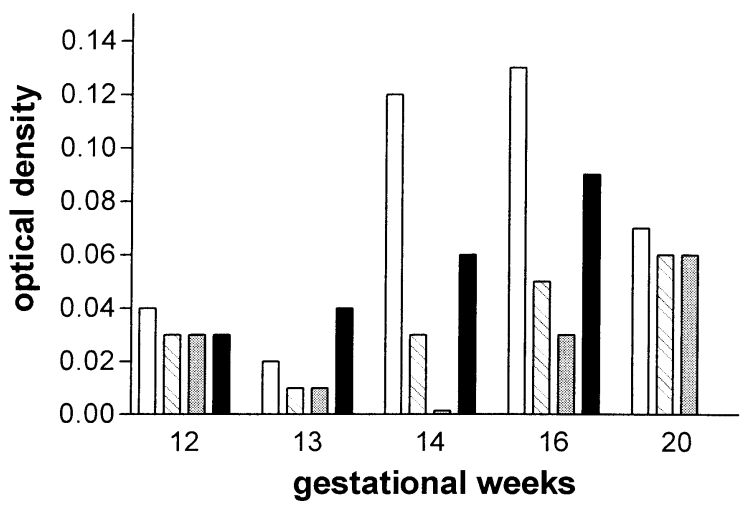

FIGURE 2. Time course of NR3A mRNA expression in the developing human cortex. NR3A transcript levels were measured in the developing human cortex during gestational weeks 12-20. Transient increases were seen in all cortical regions during this period. NR3A expression was particularly high in the marginal and ventricular zones in the second trimester. Open bars, marginal zone; striped bars, cortical plate; gray bars, intermediate zone; black bars, ventricular zone.

cortical spine density suggesting that NR3A may play a role in dendritic growth during development. ${ }^{13}$

Taken together, these data on the NR3A subunit of the NMDAR suggest that it is highly expressed in the developing human neocortex, may be associated with neuronal migration and dendritic spine density, and may play a role in developmental abnormalities associated with the pathophysiology of schizophrenia.

\section{ACKNOWLEDGMENTS}

This work was supported by Grants MH650101 (H.T.M.) and MH53327 (J.M.W.) from the National Institute of Mental Health.

\section{REFERENCES}

1. Hollmann, M. \& S. Heinemann.1994. Cloned glutamate receptors. Annu. Rev Neurosci. 17: 31-108.

2. Olney, J.W., J.W. Newcomer\& N.B. Farber. 1999. NMDA receptor hypofunction model of schizophrenia. J. Psychiatr Res. 33: 523-533.

3. Meador-Woodruff, J.H. \& D.J. Healy. 2000. Glutamate receptor expression in schizophrenic brain. Brain Res. Brain Res Rev. 31: 288-294.

4. Sucher, N.J. et al. 1995. Developmental and regional expression pattern of a novel NMDA receptor-like subunit (NMDAR-L) in the rodent brain. J. Neurosci. 15: 6509-6520. 
5. ChAn, S.F. \& N.J. Sucher. 2001. An NMDA receptor signaling complex with protein phosphatase 2A. J. Neurosci. 21: 7985-7992.

6. Chatterton, J.E. et al. 2002. Excitatory glycine receptors containing the NR3 family of NMDA receptor subunits. Nature 415: 793-798.

7. Marenco, S. \& D.R. Weinberger. 2000. The neurodevelopmental hypothesis of schizophrenia: following a trail of evidence from cradle to grave. Dev. Psychopathol. 12: $501-527$.

8. Ritter, L.M., A.S. Unis \& J.H. Meador-Woodruff. 2001. Ontogeny of ionotropic glutamate receptor expression in human fetal brain. Brain Res. Dev Brain Res. 127: $123-133$.

9. RAKIC, P. 1972. Mode of cell migration to the superficial layers of fetal monkey neocortex. J. Comp. Neurol. 145: 61-83.

10. Behar, T.N. et al. 1999. Glutamate acting at NMDA receptors stimulates embryonic cortical neuronal migration. J. Neurosci. 19: 4449-4461.

11. Akbarian, S. et al. 1993. Altered distribution of nicotinamide-adenine dinucleotide phosphate-diaphorase cells in frontal lobe of schizophrenics implies disturbances of cortical development. Arch. Gen. Psychiatry 50: 169-177.

12. AkBARIAN, S. et al. 1996. Selective alterations in gene expression for NMDA receptor subunits in prefrontal cortex of schizophrenics. J. Neurosci. 16: 19-30.

13. DAS, S. et al. 1998. Increased NMDA current and spine density in mice lacking the NMDA receptor subunit NR3A. Nature 393: 377-381. 